\title{
PENYULUHAN HUKUM EKONOMI SYARIAH TERHADAP WARGA DESA CIBIRU WETAN KECAMATAN CILEUNYI KABUPATEN BANDUNG
}

\author{
Iwan Setiawan ${ }^{1)}$ Ramdani Wahyu Sururie ${ }^{2)}$ \\ ${ }^{1)}$ Program Studi Akuntansi Syariah Fakultas Syariah dan Hukum UIN Sunan Gunung Djati Bandung \\ Email : iwansetiawan@uinsgd.ac.id \\ ${ }^{2)}$ Program Studi Hukum Keluarga Fakultas Syariah dan Hukum UIN Sunan Gunung Djati Bandung \\ Email : 124md4ni@gmail.com
}

\begin{abstract}
Abstrak
Ekonomi syariah memiliki dua hal pokok yang menjadi landasan hukum sistem ekonomi syariah yaitu Al Qur'an dan Sunnah Rasulullah, hukum-hukum yang diambil dari kedua landasan pokok tersebut secara konsep dan prinsip adalah tetap (tidak dapat berubah kapanpun dan dimana saja).Tujuan dilaksanakan penyuluhan hukum ekonomi syariah Terhadap warga Desa Cibiru Wetan Kecamatan Cileunyi Kabupaten Bandung adalah : a) Memberikan pengetahuan dan wawasan kepada peserta penyuluhan, /memberi pemahaman terhadap warga Desa Cibiru Wetan Kecamatan Cileunyi Kabupaten Bandung terkait materi hukum ekonomi syariah dan b) Memberikan pengetahuan dan wawasan serta keterampilan kapada peserta penyuluhan tentang keunggulan hukum ekonomi syariah.

Untuk memecahkan masalah yang sudah diidentifikasi dan dirumuskan tersebut di atas, agar penyuluhan dapat berjalan dengan lancar maka sebagai alternatif pemecahan masalah adalah sebagai berikut: penyuluhan dilakukan dengan pendekatan individual dan klasikal. Pendekatan klasikal dilakukan pada saat pemberian teori tentang hukum ekonomi syariah dan pendekatan individual dilakukan pada saat latihan.Berdasarkan hasil pengabdian kepada masyarakat penyuluhan hukum ekonomi syariah pada masyarakat Desa Cibiru Wetan Kecamatan Cileunyi Kabupaten Bandung; 1) Kegiatan penyuluhan hukum ekonomi syariah pada masyarakat Desa Cibiru Wetan Kecamatan Cileunyi Kabupaten Bandung memberi manfaat bagi masyarakat. Ini tampak dari antusiasnya masyarakat dalam tanya jawab dan termotivasi mengembangkan kreatifitas usahanya. Sehingga kegiatan ini perlu dilakukan secara berkelanjutan dan 2) Adapun bentuk-bentuk kegiatan yang dilakukan adalah penyuluhan secara intensif dengan tahapan sebagai berikut: Ceramah tentang pengantar pentingnya hukum ekonomi syariah; Ceramah tentang teori-teori hukum ekonomi syariah; Ceramah tentang pengembangan hukum ekonomi syariah; Demonstrasi tentang langkah-langkah penyusunan dan pengembangan hukum ekonomi syariah; Latihan simulasi penerapan hukum ekonomi syariah; dan Evaluasi hasil.. .
\end{abstract}

Kata Kunci: Hukum Ekonomi Syariah, Penyuluhan, Pengabdian Masyarakat

\begin{abstract}
Sharia economics has two legal basis of sharia economic systems, namely the Qur'an and the Sunnah of the Prophet, the laws taken from the two basic foundations in concept and principle are fixed (cannot change anytime and anywhere). The Purpose of sharia economic law counseling towards residents of Cibiru Wetan Village, Cileunyi District, Bandung Regency are: a) Providing knowledge and insight to extension participants, the residents of Cibiru Wetan Village, Cileunyi District, Bandung Regency related to sharia economic law material and b) Providing knowledge and insight and the skills of the counseling participants about the advantages of sharia economic law.

To solve the problems that have been identified and formulated above, the counseling can run as an alternative problem solving is as follows: counseling is done with individual and classical approaches. The classical approach is carried out when giving a theory about sharia economic law and an individual approach is carried out during training. The results of community service, sharia economic law counseling in the community of Cibiru Wetan Village, Cileunyi District, Bandung Regency; 1) The extension of Islamic economic law in the community of Cibiru Wetan Village, Cileunyi District, Bandung Regency has benefited the community. This is evident from the enthusiasm of the community in question and answer and motivated to develop their business creativity. So that this activity needs to be carried out continuously and 2) The forms of activities carried out are intensive counseling with the following stages: Lecture on introducing the importance of sharia economic law; Lecture on sharia economic law theories; Lecture on the development of sharia economic law; Demonstration of the steps to develop and develop sharia economic law; Simulation training on the application of sharia economic law; and evaluation of results.
\end{abstract}

Keywords: Community Service, Extension, Sharia Economic Law. 


\section{PENDAHULUAN}

Ekonomi Syariah adalah suatu cabang ilmu pengetahuan yang berupaya untuk memandang, menganalisis, dan akhirnya menyelesaikan permasalahanpermasalahan ekonomi dengan cara-cara Islam, yaitu berdasarkan atas ajaran agama Islam, yaitu Al Qur'an dan Sunnah Nabi (P3EI, 2012:17).

Ekonomi syariah memiliki dua hal pokok yang menjadi landasan hukum sistem ekonomi syariah yaitu Al Qur'an dan Sunnah Rasulullah, hukum-hukum yang diambil dari kedua landasan pokok tersebut secara konsep dan prinsip adalah tetap (tidak dapat berubah kapanpun dan dimana saja).

Berikut ini beberapa pengertian Ekonomi Syariah dari beberapa sumber buku:

1. Menurut Monzer Kahf dalam bukunya The Islamic Economy menjelaskan bahwa ekonomi Islam adalah bagian dari ilmu ekonomi yang bersifat interdisipliner dalam arti kajian ekonomi syariah tidak dapat berdiri sendiri, tetapi perlu penguasaan yang baik dan mendalam terhadap ilmu-ilmu syariah dan ilmu-ilmu pendukungnya juga terhadap ilmu-ilmu yang berfungsi sebagai tool of analysis seperti matematika, statistik, logika dan ushul fiqih (Rianto dan Amalia, 2010:7).

2. M.A. Mannan mendefinisikan ilmu ekonomi syariah sebagai suatu ilmu pengetahuan sosial yang mempelajari masalah-masalah ekonomi rakyat yang diilhami oleh nilai-nilai islam (Mannan, 1992:15).

3. Definisi ekonomi syariah berdasarkan pendapat Muhammad Abdullah Al-Arabi (1980:11), Ekonomi Syariah merupakan sekumpulan dasar-dasar umum ekonomi yang kita simpulkan dari Al Qur'an dan Assunnah, dan merupakan bangunan perekonomian yang kita dirikan di atas landasan dasar-dasar tersebut sesuai dengan tiap lingkungan dan masa.

Kurangnya kesadaran masyarakat Desa Cibiru Wetan Kecamatan Cileunyi Kabupaten Bandung terhadap Hukum Ekonomi Syariah berimbas pada rendahnya tingkat kesadaran untuk berinterkasi ekonomi dengan system ekonomi syariah.

\section{Identifikasi Masalah}

Tujuan Ekonomi Syariah selaras dengan tujuan dari syariat Islam itu sendiri (maqashid asy syari'ah), yaitu mencapai kebahagiaan di dunia dan akhirat (falah) melalui suatu tata kehidupan yang baik dan terhormat (hayyah thayyibah). Tujuan falah yang ingin dicapai oleh Ekonomi Syariah meliputi aspek mikro ataupun makro, mencakup horizon waktu dunia atau pun akhirat (P3EI, 2012:54).

Seorang fuqaha asal Mesir bernama Prof. Muhammad Abu Zahrah mengatakan ada tiga sasaran hukum Islam yang menunjukkan bahwa Islam diturunkan sebagai rahmat bagi seluruh umat manusia, yaitu (Rahman, 1995:84):

1. Penyucian jiwa agar setiap muslim bisa menjadi sumber kebaikan bagi masyarakat dan lingkungannya.

2. Tegaknya keadilan dalam masyarakat. Keadilan yang dimaksud mencakup aspek kehidupan di bidang hukum dan muamalah.

3. Tercapainya maslahah (merupakan puncaknya). Para ulama menyepakati bahwa maslahah yang menjad puncak sasaran di atas mencakup lima jaminan dasar, yaitu: keselamatan keyakinan agama (al din), kesalamatan jiwa (al nafs), keselamatan akal (al aql), keselamatan keluarga dan keturunan (al nasl) dan keselamatan harta benda (al mal).

Pelaksanaan ekonomi syariah harus menjalankan prinsip-prinsip sebagai berikut (Sudarsono, 2002:105):

1. Berbagai sumber daya dipandang sebagai pemberian atau titipan dari Allah swt kepada manusia.

2. Islam mengakui pemilikan pribadi dalam batas-batas tertentu.

3. Kekuatan penggerak utama Ekonomi Syariah adalah kerja sama.

4. Ekonomi Syariah menolak terjadinya akumulasi kekayaan yang dikuasai oleh segelintir orang saja.

5. Ekonomi Syariah menjamin pemilikan masyarakat dan penggunaannya direncanakan untuk kepentingan banyak orang.

6. Seorang muslim harus takut kepada Allah swt dan hari penentuan di akhirat nanti.

7. Zakat harus dibayarkan atas kekayaan yang telah memenuhi batas (nisab).

8. Islam melarang riba dalam segala bentuk.

Layaknya sebuah bangunan, sistem ekonomi syariah harus memiliki fondasi yang berguna sebagai landasan dan mampu menopang segala bentuk kegiatan ekonomi guna mencapai tujuan mulia. Berikut ini merupakan prinsipprinsip dasar dalam ekonomi syariah, diantaranya adalah (Zainuddin Ali, 2008):

1. Tidak melakukan penimbunan (Ihtikar). Penimbunan, dalam bahasa Arab disebut dengan al-ihtikar. Secara umum, ihtikar dapat diartikan sebagai tindakan pembelian barang dagangan dengan tujuan untuk menahan atau menyimpan barang tersebut dalam jangka waktu yang lama, sehingga barang tersebut dinyatakan barang langka dan berharga mahal.

2. Tidak melakukan monopoli. Monopoli adalah kegiatan menahan keberadaan barang untuk tidak dijual atau tidak diedarkan di pasar, agar harganya menjadi mahal. Kegiatan monopoli merupakan salah satu hal yang dilarang dalam Islam, apabila monopoli diciptakan secara sengaja dengan cara menimbun barang dan menaikkan harga barang. 
3. Menghindari jual-beli yang diharamkan. Kegiatan jualbeli yang sesuai dengan prinsip Islam, adil, halal, dan tidak merugikan salah satu pihak adalah jual-beli yang sangat diridhai oleh Allah swt. Karena sesungguhnya bahwa segala hal yang mengandung unsur kemungkaran dan kemaksiatan adalah haram hukumnya.

\section{TEORI YANG DIJADIKAN DASAR PKM \\ Pengertian Fiqih Mu'amalah.}

Pengertian fiqih mu'amalah tersusun atas dua kata, yaitu fiqih dan mu'amalah.Kata fiqih secara etimologis berakar pada kata kerja yaitu : فَقَََ - يُفَقِهُ - فَفْهَا - آَنْ فَهْمَهُ yang artinya paham, mengerti, pintar dan kepintaran. Menunjukkan kepada "maksud sesuatu" atau "ilmu pengetahuan".Secara terminologis, fiqih adalah hukumhukum syara' yang bersifat praktis (amaliah) yang diperoleh dari dalil-dalil terperinci. Sedang mu'amalah secara bahasa berasal dari kata : "aamala - yuaamilu mu'amalatan", yang artinya saling berbuat dan saling mengamalkan. Sedangkan mu'amalah secara terminologi dapat diartikan sebagai aturan-aturan Allah yang mengatur hubungan tentang manusia dengan manusia dalam usahanya untuk mendapatkan alat-alat keperluan jasmaninya dengan cara yang paling baik.

Menurut pengertian di atas, fiqih mu'amalah dapat didefinisikan sebagai hukum syara' yang bersifat amaliah yang mengatur hubungan manusia dengan manusia lainnya dalam usahanya untuk memenuhi kebutuhan hidup.

\section{Pembagian Fiqih Mu'amalah.}

Pembagian fiqih mu'amalah ini sangat berkaitan dengan pandangan fuqoha dalam mendefinisikan pengertian fiqih mu'amalah dalam arti luas atau arti sempit. Menurut Ibn 'Abidin, fiqih mu'amalah dibagi menjadi lima bagian :

a. Mu'amalah Maliyah ( Hukum Kebendaan).

b. Munakahat( Hukum Perkawinan).

c. Muhasanat (Hukum Acara).

d. Amanat dan "Ariyah (Pinjaman).

e. Tirkah( Harta Peninggalan).

Sedangkan Al-Fikri dalam kitabnya “Al-Mu'amalah alMadiyah wa al-Adabiyah" menyatakan, bahwa mu'amalah dibagi menjadi dua bagian, sebagi berikut :

1. Al-Mu'amalah al-Madiyah, yaitu mu'amalah yang menkaji dari dimesi obyeknya.Sebagian ulama' berpendapat bahwa mu'amalah al-madiyah adalah mu'amalah yang bersifat kebendaan, karena obyek fiqih mu'amalah meliputi benda yang halal, haram dan syubhat untuk diperjualbelikan; benda-benda yang membahayakan; dan benda-benda yang mendatangkan kemaslahatan bagi manusia.Karena itu aktifitas bisnis seorang muslim tidak hanya berorientasi untuk mendapatkan keuntungan materiil semata, tetapi praktek bisnis tersebut harus dilandasi oleh nilai-nilai sakral agama, dalam rangka untuk mendapatkan ridho Allah SWT.

2. Al-Mu'amalah al-Adabiyah, yaitu mu'amalah yang ditinjau dari cara tukar-menukar benda, yang bersumber dari panca indera manusia, yang unsur penegaknya adalah hak-hak dan kewajibankewajiban, misalnya jujur, hasud, dengki dan dendam.

Mu'amalah al-Adabiyah yang dimaksud adalah aturanaturan Allah yang wajib diikuti berkaitan dengan aktifitas manusia dalam hidup bermasyarakat yang ditinjau dari segi subyeknya, yaitu manusia sebagai pelakunya.Adabiyah ini berkisar dalam keridhaan antara kedua belah pihak saat melakukan akad, sehingga tidak boleh terjadi unsur dusta, atau menipu di dalamnya.

\section{Ruang Lingkup Fiqh Mu'amalah.}

Berdasarkan pembagian Fiqih Mu'amalah di atas, maka ruang lingkup Fiqih Mu'amalah terbagi menjadi dua, yaitu :

\section{Ruang lingkup Mu'amalah Adabiyah.}

Ruang lingkup mu'amalah yang bersifat adabiyah adalah ijab dan qabul, saling meridhoi, tidak ada keterpaksaan dari salah satu pihak, hak dan kewajiban, kejujuran pedangan, penipuan, pemalsuan, penimbunan dan segala sesuatu yang terdapat kaitannya dengan pendistribusian harta dalam hidup bermasyarakat.

2. Ruang lingkup Mu'amalahMadiyah.

Ruang lingkup pembahasan Mu'amalah Madiyah ialah masalah jual beli (al-bai' wa al-tijarah), gadai (al-rahn), jaminan dan tanggungan (kafalah dan dhaman), perseroan atau perkongsian (al-syirkah), perseroan harta dan tenaga (al-mudharabah), sewa-menyewa (al-ijarah), pemberian hak guna pakai (al-a'riyah), barang titipan (al-wadhi'ah), barang temuan (al-luqathah), garapan tanah (almuzara'ah), sewa menyewa tanah (al-mukhabarah), upah (ujrah al-'amal), gugatan (syuf'ah), sayembara (al-ji'alah), pembagian kekayaan bersama (al-qismah), pemberian (alhibbah), pembebasan (al-ibra), damai (as-sulhu), dan ditambah dengan permasalahan kontemporer (almungasirah) seperti masalah bunga bank, asuransi, kredit, dan lain-lain.

4. Perbedaan mendasar sistem ekonomi islam dengan ekonomi konvensional.

Tabel 1 menjelaskan beberapa perbedaan mendasar dalam kedua sistem ekonomi ini. 
Tabel 1. Perbedaan system ekeonomi Islam dan ekonomi konvensional

\begin{tabular}{|c|c|c|c|}
\hline No & Isu & Islam & Konvensional \\
\hline 1 & Sumber & Al-Quran & Daya fikir manusia \\
\hline 2 & Motif & Ibadah & $\begin{array}{c}\text { Rasional } \\
\text { matearialism }\end{array}$ \\
\hline 3 & Paradigma & Syariah & Pasar \\
\hline 4 & Pondasi dasar & Muslim & Manusia ekonomi \\
\hline 5 & $\begin{array}{c}\text { Landasan } \\
\text { fillosofi }\end{array}$ & Falah & $\begin{array}{c}\text { Utilitarian } \\
\text { individualism }\end{array}$ \\
\hline 6 & Harta & Pokok kehidupan & Asset \\
\hline 7 & Investasi & Bagi hasil & Bunga \\
\hline 8 & $\begin{array}{l}\text { Distribusi } \\
\text { kekayaan }\end{array}$ & $\begin{array}{l}\text { Zakat, infak, } \\
\text { shodaqoh, hibah, } \\
\text { hadiah, wakaf dan } \\
\text { warisan. }\end{array}$ & Pajak dan tunjangan \\
\hline 9 & $\begin{array}{l}\text { Konsumsi- } \\
\text { produksi }\end{array}$ & $\begin{array}{l}\text { Maslahah, } \\
\text { kebutuhan dan } \\
\text { kewajiban }\end{array}$ & $\begin{array}{l}\text { Egoism, } \\
\text { materialism, dan } \\
\text { rasionalisme }\end{array}$ \\
\hline 10 & $\begin{array}{l}\text { Mekanisme } \\
\text { pasar }\end{array}$ & $\begin{array}{l}\text { Bebas dan dalam } \\
\text { pengawasan }\end{array}$ & Bebas \\
\hline 11 & $\begin{array}{c}\text { Pengawas } \\
\text { pasar }\end{array}$ & Wilayatul Hisba & N/A \\
\hline 12 & $\begin{array}{l}\text { Fungsi } \\
\text { Negara }\end{array}$ & $\begin{array}{l}\text { Penjamin } \\
\text { kebutuhan } \\
\text { minimal dan } \\
\text { pendidikan } \\
\text { melalui baitul mal }\end{array}$ & $\begin{array}{c}\text { Penentu kebijakan } \\
\text { melalui } \\
\text { Departemen- } \\
\text { departemen }\end{array}$ \\
\hline 13 & $\begin{array}{l}\text { Bangunan } \\
\text { ekonomi }\end{array}$ & $\begin{array}{l}\text { Bercorak } \\
\text { perekonomian real }\end{array}$ & $\begin{array}{l}\text { Dikotomi sektoral } \\
\text { yang sejajar } \\
\text { ekonomi riil dan } \\
\text { moneter }\end{array}$ \\
\hline
\end{tabular}

Perbedaan yang sering didengar dari kedua sistem ekonomi ini disampaikan pada Tabel 2.

Tabel 2. Perbedaan bunga dan bagi hasil

\begin{tabular}{|c|c|}
\hline Bunga & Bagi Hasil \\
\hline $\begin{array}{c}\text { Penentuan bunga dibuat pada } \\
\text { waktu akad dengan asumsi } \\
\text { usaha akan selalu } \\
\text { menghasilkan keuntungan }\end{array}$ & $\begin{array}{c}\text { Penentuan besarnya nisbah bagi } \\
\text { hasil disepakati pada waktu akad } \\
\text { dengan berpedoman pada } \\
\text { kemungkiinan untung rugi }\end{array}$ \\
\hline $\begin{array}{c}\text { Besarnya } \\
\text { presentasididasarkan pada } \\
\text { jumlah modal yang } \\
\text { dipinjamkan. }\end{array}$ & $\begin{array}{c}\text { Besarnya rasio bagi hasil } \\
\text { didasarkan pada jumlah } \\
\text { keuntungan yang diperoleh. }\end{array}$ \\
\hline $\begin{array}{c}\text { Bunga dapat mengambang } \\
\text { dan besarnnya naik turun } \\
\text { sesuai dengan naik turunnya } \\
\text { kondisi ekonomi }\end{array}$ & $\begin{array}{c}\text { Rasio bagi hasil tetap tidak berubah } \\
\text { selama akad masih berlaku, kecuali } \\
\text { diubah atas kesepakatan bersama. }\end{array}$ \\
\hline $\begin{array}{c}\text { Pembayaran bunga tetap } \\
\text { seperti yang dijanjikan tanpa } \\
\text { mempertimbangkan apakah } \\
\text { usaha yang dijalankan untung } \\
\text { atau rugi. }\end{array}$ & $\begin{array}{c}\text { Bagi hasil bergantung pada } \\
\text { keuntungan usaha yang dijalankan. } \\
\text { Bila usaha merugi, kerugian } \\
\text { ditangggung bersama. }\end{array}$ \\
\hline $\begin{array}{c}\text { Jumlah pembayaran bunga } \\
\text { tidak meningkat sekalipun } \\
\text { keuntungan berlipat }\end{array}$ & $\begin{array}{c}\text { Jumlah pembagian laba meningkat } \\
\text { sesuai dengan peningkatan } \\
\text { keuntungan. }\end{array}$ \\
\hline $\begin{array}{c}\text { Eksistensi bunga diragukan } \\
\text { kalau tidak dikecam) oleh } \\
\text { semua agama. }\end{array}$ & $\begin{array}{c}\text { Tidak ada yang meragukan } \\
\text { keabsahan bagi hasil }\end{array}$ \\
\hline
\end{tabular}

\section{METODOLOGI PENGABDIAN}

Untuk memecahkan masalah yang sudah diidentifikasi dan dirumuskan tersebut di atas, agar penyuluhan dapat berjalan dengan lancar maka sebagai alternatif pemecahan masalah adalah sebagai berikut: penyuluhan dilakukan dengan pendekatan individual dan klasikal. Pendekatan klasikal dilakukan pada saat pemberian teori tentang hukum ekonomi syariah dan pendekatan individual dilakukan pada saat latihan. Adapun metode yang digunakan adalah:

\section{Ceramah bervariasi.}

Metode ini dipilih untuk menyampaikan konsepkonsep yang penting untuk dimengerti dan dikuasai oleh peserta penyuluhan. Penggunaan metode ini dengan pertimbangan bahwa metode ceramah yang dikombinasikan dengan gambar-gambar, animasi dan display dapat memberikan materi yang relatif banyak secara padat, cepat dan mudah. Materi yang diberikan meliputi:
1 Memahami Konsep Fiqh Muamalah
2 Memahami Konsep Harta dalam Islam
3 Memahami Konsep Akad
4 Memahami Konsep riba
5 Memahami Konsep Murabahah

\section{Demonstrasi}

Metode ini dipilih untuk menunjukkan suatu proses kerja yaitu tahap-tahap pengembangan hukum ekonomi syariah. Demonstrasi dilakukan oleh instruktur di hadapan peserta sehingga peserta dapat mengamati secara langsung metode dan teknik pengembangan hukum ekonomi syariah.

\section{Latihan}

Metode ini digunakan untuk memberikan tugas kepada peserta penyuluhan untuk membuat simulasi penerapan hukum ekonomi Syariah.

\section{PELAKSANAAN KEGIATAN}

Kegiatan penyuluhan ini dilaksanakan dan diikuti oleh perwakilan masyarakat dari 19 RW yang ada di Desa Cibiru Wetan Kecamatan Cileunyi Kabupaten Bandung.

\section{HASIL DAN PEMBAHASAN}

Kegiatan pengabdian ini terselenggara atas kerjasama antara UIN Sunan Gunung Djati dengan dengan masyarakat Desa Cibiru Wetan Kabupaten Bandung tahun 2018. Kegiatan penyuluhan ini merupakan salah satu tahapan penting dari kegiatan pengabdian kepada masyarakat sebagai bagian Tridarma Perguruan Tinggi yang dilaksanakan pada tanggal 07 Mei-27 Agustus 2018. Penyuluhan dilakukan di Aula Kantor Desa Cibiru Wetan Kabupaten Bandung. Yang memberI kata sambutan dalam penyuluhan ini adalah sekretaris Desa Cibiru Wetan 
Kabupaten Bandung. Sedangkan sebagai narasumber kegiatan penyuluhan ini adalah Dr. Iwan Setiawan, S.Ag., M.Pd., M.E.Sy dan Bapak Dr. H. Ramdani Wahyu Sururie, M.Ag., M.Si yang kedua-duanya merupakan dosen Fakultas Syariah dan Hukum UIN Sunan Gunung Djati . Selain memberikan ceramah pada penyuluhan tersebut, narasumber juga membagikan brosur hukum ekonomi syariah. Kegiatan berlangsung lancar dengan suasana kenyamanan desa yang sangat kental. Dalam pelaksanaannya kegiatan penyuluhan ini dihadiri oleh berbagai lapisan masyarakat. Tokoh masyarakat yang hadir antara lain Bapak Kepala Desa Cibiru Wetan, Bapak Sekretaris Cibiru Wetan, ibu-ibu PKK, beserta seluruh RT dan RW. Selain tokoh masyarakat juga dihadiri oleh ketua organisasi di masyarakat, ketua kelompok usaha, serta pengusaha-pengusaha kecil dan menengah. Masyarakat yang hadir tampak sangat antusias mendengarkan penyuluhan yang disampaikan, hal ini tampak dari banyaknya masyarakat yang bertanya dan ingin mendapatkan penjelasan lebih mendalam bagaimana hukum ekonomi syraiah bisa mereka kembangkan di wilayah desa mereka.

Sebagai wujud nyata dari kegiatan pengabdian ini sebagai luarannya adalah terbentuknya "kelompok ekonomi syariah Cibiru Wetan" yang dibangun atas kerjasama dengan masyarakat serta di desa ini.

Harapan masyarakat tersebut bisa bermanfaat untuk jangka panjang sehingga mereka sangat memerlukan bimbingan dari pihak-pihak berkompeten. Kegiatan penyuluhan dilakukan dengan metode ceramah, tanya jawab serta mempertontonkan film-film proses-proses kegiatan ekonomi syariah masyarakat pedesaan dari daerah lain. Pemutaran film ini juga bermaksud untuk memotivasi keinginan masyarakat untuk mengembangkan ide-ide kreatif yang dimiliki untuk memanfaatkan sumberdaya yang tersedia di wilayahnya. Potensi sumberdaya Cibiru Wetan sangat beragam dan prospek dikembangkan untuk mendukung geliat ekonomi syariah masyarakat.

Di sini memiliki tempat yang sangat menarik untuk dikembangkan sebagai upaya meningkatkan kesejahteraan. Sumberdaya yang terpenting yang dimiliki adalah sumberdaya insani yang dimiliki desa untuk pengembangan ekonomi kreatif. Karena itu substansi isi materi penyuluhan yang disampaikan disesuaikan dengan potensi sumberdaya yang ada di desa.

Pelaksanaan penyuluhan yang diberikan kepada masyarakat sudah merupakan langkah tepat untuk memotivasi selera usaha masyarakat. Adanya hubungan peranan penyuluhan terhadap peningkatan pendapatan masyarakat di pedesaan merupakan suatu hasil dari proses penyuluhan yang telah dilaksanakan.

Melalui penyuluhan masyarakat mendapatkan informasi dan 17 wawasan, sehingga masyarakat dapat memahami secara mendalam tentang ekonomi kreatif serta manfaatnya bagi peningkatan pendapatannya. Bahkan menurut Saadah, Anwar sulili dan Bining Deserama (2011) menyebutkan bahwa pemahaman masyarakat sebelum mendapatkan penyuluhan dengan sesudah mendapatkan penyuluhan mempengaruhi pemahamannya hingga $56 \%$. Keberhasilan penyuluh hukum ekonomi syariah yang ditujukan dengan diterimanya ide baru berlanjut sampai digunakannya ide baru oleh masyarakat (fungsi pelaku utama) berlangsung dalam suatu sistem penyuluhan hukum ekonomi syariah yang di dalamnya ada beberapa fungsi yang dapat saling mempengaruhi yaitu

1) fungsi penelitian,

2) fungsi pengaturan,

3) fungsi pelayanan, dan

4) fungsi penyuluhan (Dayat, tanpa tahun).

Berdasarkan fungsi tersebut kegiatan ini memiliki fungsi penyuluhan, ini tampak dari aktifitas masyarakat setempat, dengan mudah menerima pengetahuan baru dan berkeinginan mengimplementasikannya. Namun untuk memperoleh hasil yang lebih maksimal hal yang dapat dilakukan adalah diperlukan kegiatan lanjutan yang bersifat pendampingan masyarakat sehingga mereka terus bisa menekuni usaha yang akan dibuat. Hambatan yang ditemui pada saat penyuluhan adalah menyesuaikan jadwal masyarakat dengan jadwal kegiatan karena hampir seluruh mereka bekerja sebagai pekerja di siang hari.

\section{Ucapan Terima Kasih}

Ucapan terimakasih diucapkan kepada bapak Rektor UIN Sunan Gunung Djati yang telah memberi kesempatan kami melakukan pengabdian kepada masyarakat, terimakasih juga diucapkan kepada Bapak kepala Desa Cibiru Wetan serta seluruh masyarakat yang terlibat dalam kegiatan pengabdian ini..

\section{PENUTUP}

\section{Kesimpulan}

1. Kegiatan penyuluhan hukum ekonomi syariah pada masyarakat Desa Cibiru Wetan Kecamatan Cileunyi Kabupaten Bandung memberi manfaat bagi masyarakat. Ini tampak dari antusiasnya masyarakat dalam tanya jawab dan termotivasi mengembangkan kreatifitas usahanya. Sehingga kegiatan ini perlu dilakukan secara berkelanjutan.

2. Adapun bentuk-bentuk kegiatan yang dilakukan adalah penyuluhan secara intensif dengan tahapan sebagai berikut:

a. Ceramah tentang pengantar pentingnya hukum ekonomi syariah;

b. Ceramah tentang teori-teori hukum ekonomi syariah; 
c. Ceramah tentang pengembangan hukum ekonomi syariah;

d. Demonstrasi tentang langkah-langkah penyusunan dan pengembangan hukum ekonomi syariah;

e. Latihan simulasi penerapan hukum ekonomi syariah; dan

f. Evaluasi hasil.

\section{DAFTAR PUSTAKA}

Abu Yasid, Islam Moderat, (Jakarta: Erlangga, 2014).

Adin, Ahmad, dan Asih,"Fiqih klasik dan kontemporer", dalam laman http://azyieh.blogspot.co.id/2014/11/fiqh-klasik-dankontemporer.html, di unduh pada 26 September 2016.

Agus Arwani, "Epistemologi Hukum Ekonomi Islam (Muamalah)", dalam jurnal RELIGIA Vol. 15 No. 1, April 2012. (125-146).

Agus Supriyanto, "Ijtihad: Makna dan Relasinya dengan Syari'ah, Fiqih, dan Ushul Fiqih", dalam jurnal Maslahah, Vol.1, No. 1, Juli 2010, (1-20).

Fadllan, "GADAISYARIAH; Perspektif Fikih Muamalah dan Aplikasinya dalam Perbankan”, dalam jurnal alIhkâm, Vol.1 No.1 Juni 201432 (30-31).

Febby Febiyanti, "Makalah Fiqih Muamalah", dalam laman http://justbloggue.blogspot.co.id/2013/07/makalah-fiqihmuamalah.html

Iffatin Nur, Epistemologi Fiqih, (Tulungagung: STAIN Tulungagung Press, 2013).

Imam Mustofa, Fiqih Mu'amalah Kontemporer, (Jakarta: PT. RajaGrafindo Persada,2016).

Nizzaruddin, Fiqih Muamalah, (Yogyakarta: Idea Press, 2003).

Nurfaizal, "Prinsip-Prinsip Muamalah Dan Inplementasinya Dalam Hukum Perbankan Indonesia ", dalam jurnal Hukum Islam, Vol. XIII No. 1 Nopember 2013, (192-205).

Syamsul Hilal ,"Fiqih Dan Permasalahan Kontemporer", dalam jurnal ASAS Vol. 4, No 1 (2012) Januari 2012 (1-9).

"Makalah Konsep Dasar Fiqih Muamalah", dalam laman http://syariah99.blogspot.co.id/2013/05/konsep-dasarfiqh-muamalah.html. Diunduh pada 26 September 2016.

Candra, Reo.2012.Akad Tabarru' dan Tijarah.Riau:Universitas Islam Negeri Sultan Syarif Kasim.

Darsuki, Ahmad.2012.Teori Akad dan Implikasinya Dalam Bisnis Islam.Jogjakarta:Universitas Islam Indonesia.
H.M. Azhari, M.HI.Jenis - Jenis Akad Dalam Perbankan Syari'ah (Tabarru' dan Tijarah).Kalimantan Timur:Pengadilan Agama Tanah Grogot. Dalam : http://pa-tanahgrogot.net/a. 